This item was submitted to Loughborough's Research Repository by the author.

Items in Figshare are protected by copyright, with all rights reserved, unless otherwise indicated.

\title{
Plucking models of business cycle fluctuations: evidence from the G-7
} \section{countries}

PLEASE CITE THE PUBLISHED VERSION

PUBLISHER

(c) Loughborough University

LICENCE

CC BY-NC-ND 4.0

\section{REPOSITORY RECORD}

Mills, Terence C., and Ping Wang. 2019. "Plucking Models of Business Cycle Fluctuations: Evidence from the G-7 Countries". figshare. https://hdl.handle.net/2134/1126. 
This item was submitted to Loughborough's Institutional Repository by the author and is made available under the following Creative Commons Licence conditions.

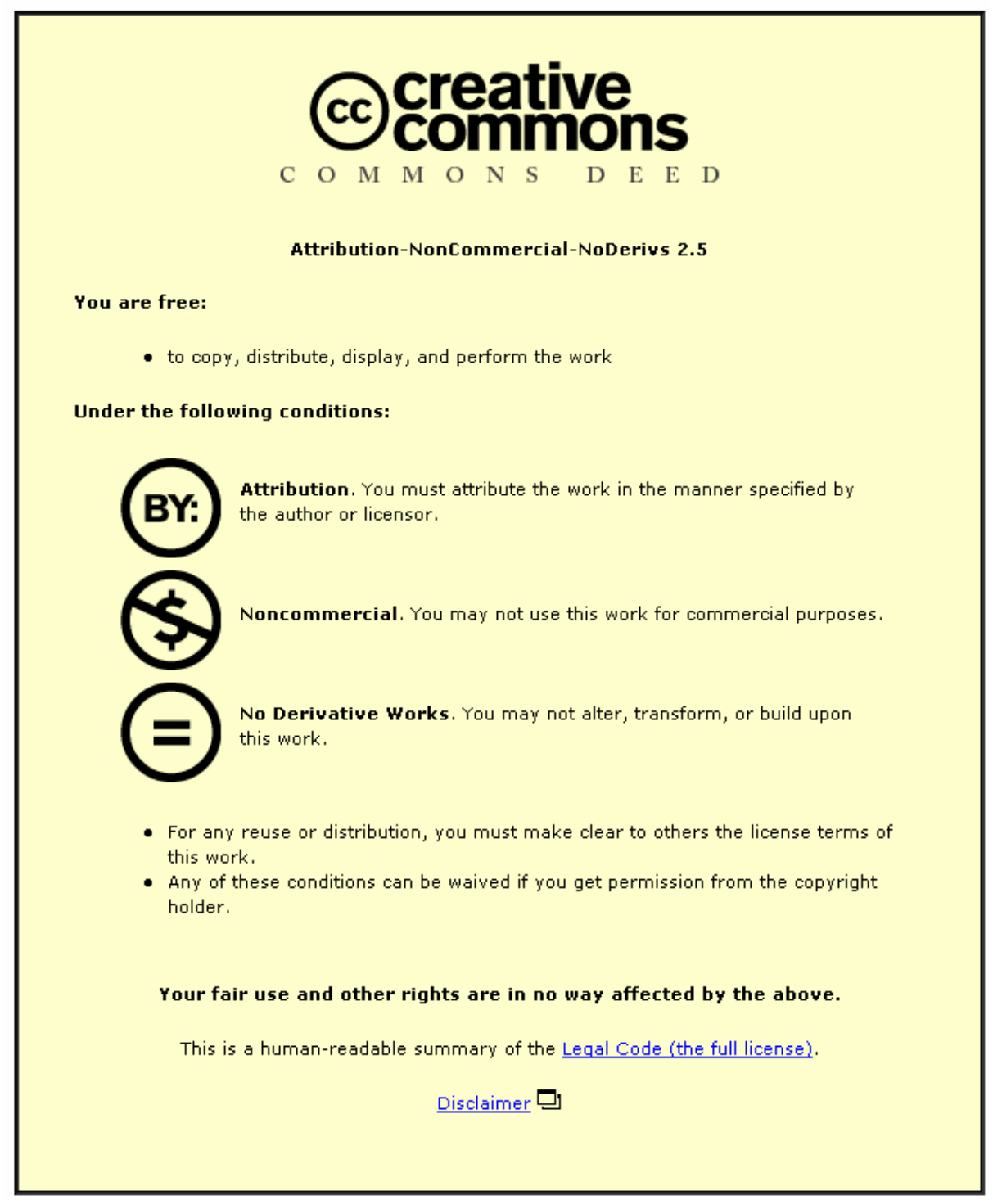

For the full text of this licence, please go to: http://creativecommons.org/licenses/by-nc-nd/2.5/ 


\section{Department of Economics}

\section{Business Cycle Volatility and EConomic Growth RESEARCH PAPER NO. 00-3}

Plucking Models of Business CyCLE FLUCTUATIONS: EVIDENCE FROM THE G-7 COUNTRIES

\section{Terence C. Mills and Ping Wang}

August 2000

This paper forms part of the ESRC funded project (Award No. L1382511013) "Business Cycle Volatility and Economic Growth: A Comparative Time Series Study", which itself is part of the Understanding the Evolving Macroeconomy Research programme. 
Loughborough University 


\begin{abstract}
Friedman's 'plucking' model, in which output cannot exceed a ceiling level but is occasionally plucked downward by recessions, is tested using Kim and Nelson's formal econometric specification on output data from the G-7 countries. Considerable support for the model is obtained, leading us to conclude that during normal periods, output seems to be driven mostly by permanent shocks, but during recessions and highgrowth recoveries, transitory shocks dominate. During these periods macroeconomic models that emphasise demand-oriented shocks, rather than real business cycle type models, may thus be more appropriate.
\end{abstract}

Keywords: Business Cycle Asymmetry, State Space Models, G-7 COUNTRIES, MARKOV SWITCHING. 


\section{Introduction}

The recent interest in business cycle asymmetry has brought back into fashion the "plucking model" suggested by Milton Friedman more than 30 years ago. Friedman (1964, 1993) noticed a striking asymmetry in the correlations between succeeding phases of the business cycle - the amplitude of contractions is strongly correlated with succeeding expansions, but the amplitude of these expansions is uncorrelated with the amplitude of succeeding contractions. He thus proposed a model of business cycles in which he likened the path of output to a string attached to the underside of a board, which may be held at an angle to represent secular growth. The board represents an upper limit, or ceiling, to output, while the string is plucked downward by recessionary shocks at irregular intervals. The extent of the output decline will vary across recessions, but output will always rebound to the ceiling level, so that recessions can only have temporary effects on output. Friedman's proposal has resulted in numerous studies of asymmetry, but a formal test of the plucking model has only recently been provided by Kim and Nelson (1999a), in which a concise survey of asymmetric business cycle research may also be found.

Existing attempts to incorporate asymmetry into time series models of economic fluctuations typically have been limited to the growth rate of output or to its trend component. Observing this, Kim and Nelson (1999a) develop a model that is able to estimate the importance of downward shocks to both trend and cycle, and to test the plucking hypothesis against a symmetric trend-plus-cycle alternative such as that proposed by Clark (1987). The feature of their model is that it incorporates asymmetric movements of business fluctuations away from trend and asymmetric persistence of shocks during recessionary and normal times. They show that the stochastic behaviour of quarterly U.S. output is well characterised by Friedman's plucking model, i.e., output is occasionally plucked down by recession and the cyclical or transitory component exhibits asymmetric behaviour.

Most research on business cycle asymmetry is based on data from the U.S., although Goodwin and Sweeney (1993) focus on eight OECD countries. There have been several recent studies of the U.K. business cycle, notably Artis and Zhang (1999), Birchenhall et al (1999), Simpson et al (2000) and Öcal and Osborn (2000). These have applied Markov-switching or smooth transition models to examine growth in the two states of recession and expansion, but they do not decompose output into a trend and a cycle in the two states, or investigate business cycle asymmetry in the sense of plucking. To further our understanding of asymmetric output movements, we test Friedman's plucking model by extending Kim and Nelson's (1999a) work to the G-7 countries and present cross-country comparisons. 


\section{Model Specification}

The novel feature of Kim and Nelson's specification is that they allow first-order Markov switching variables in both the trend and cycle components, thus allowing both plucking and asymmetric fluctuations around a stochastic trend. Consider the following unobserved component model in which the logarithm of output, $y_{t}$, is decomposed into trend, $\tau_{t}$, and transitory, $c_{t}$, components:

$$
y_{t}=\tau_{t}+c_{t}
$$

To allow for regime shifts or asymmetric deviations of $y_{t}$ from its trend, it is assumed that innovations to the transitory component are a mixture of two different types of shocks:

$$
\begin{aligned}
& c_{t}=\phi_{1} c_{t-1}+\phi_{2} c_{t-2}+\pi_{S_{t}}+u_{t}, \\
& \pi_{S_{t}}=\pi S_{t}, \quad \pi \neq 0, \\
& u_{t} \sim N\left(0, \sigma_{u, s_{t}}^{2}\right), \quad \sigma_{u, s_{t}}^{2}=\sigma_{u, 0}^{2}\left(1-S_{t}\right)+\sigma_{u, 1}^{2} S_{t}, \quad S_{t}=0 \text { or } 1 .
\end{aligned}
$$

Here $\pi_{S_{t}}$ is an asymmetric discrete shock, which is dependent upon an unobserved variable, $S_{t}$, while $u_{t}$ is the usual symmetric shock. $S_{t}$ is an indicator variable that evolves according to a first-order Markov-switching process as in Hamilton (1989):

$$
\begin{aligned}
& P\left[S_{t}=1 \mid S_{t-1}=1\right]=p \\
& P\left[S_{t}=0 \mid S_{t-1}=0\right]=q
\end{aligned}
$$

During 'normal times', $S_{t}=0$ and the economy is near to potential or trend output. During 'recessions', however, $S_{t}=1$ and the economy is hit by a transitory shock, possibly with a negative expected value if $\pi<0$. If this is the case, then aggregate demand or other disturbances are 'plucking' output down. Equation (2) allows for the possibility that the variance of the shock may be different in the two regimes. In the absence of such shocks, $c_{t}$ evolves as a second order autoregressive process and hence can display both persistence and pseudo-cyclical behaviour.

The specification of the trend component in (1) is consistent with Friedman's (1993) suggestion that potential output may be approximated by a random walk, with various types of disturbances producing perturbations to it:

$$
\begin{aligned}
& \tau_{t}=g_{t-1}+\tau_{t-1}+v_{t}, \\
& g_{t}=g_{t-1}+w_{t},
\end{aligned}
$$




$$
\begin{aligned}
& v_{t} \sim N\left(0, \sigma_{v, S_{t}}^{2}\right), \quad w_{t} \sim N\left(0, \sigma_{w}^{2}\right), \\
& \sigma_{v, S_{t}}^{2}=\sigma_{v, 0}^{2}\left(1-S_{t}\right)+\sigma_{v, 1}^{2} S_{t},
\end{aligned}
$$

The stochastic trend $\tau_{t}$ is thus subjected to two shocks - to its level, through $v_{t}$, and to its growth rate, through $w_{t}$. Specifying trend growth, $g_{t}$, to be stochastic allows the possibility of, for example, productivity slowdowns in output. The above specifications again allow for the possibility that the variance of the level shock may be different across regimes. On the other hand, the variance of $g_{t}$ is assumed not to be systematically different across regimes.

In the transitory component, the term $\pi_{S_{t}}$ is incorporated to account for potential asymmetric behaviour. In addition, if $\sigma_{u, S_{t}}^{2}=0$ with $\pi<0$, this implies the existence of a trend ceiling or maximum feasible output, as suggested in Friedman's plucking model. Thus, the regime characterised by $S_{t}=1$ and $\pi<0$ would be interpreted as a period during which the economy is being plucked down below its trend ceiling level.

The model can be given the state-space representation

$$
\begin{aligned}
& y_{t}=\left[\begin{array}{llll}
1 & 1 & 0 & 0
\end{array}\right]\left[\begin{array}{l}
\tau_{t} \\
c_{t} \\
c_{t-1} \\
g_{t}
\end{array}\right]=H \xi_{t} \quad \text { Observation equation } \\
& \xi_{t}=\left[\begin{array}{c}
0 \\
\pi_{S_{t}} \\
0 \\
0
\end{array}\right]+\left[\begin{array}{cccc}
1 & 0 & 0 & 1 \\
0 & \phi_{1} & \phi_{2} & 0 \\
0 & 1 & 0 & 0 \\
0 & 0 & 0 & 1
\end{array}\right] \xi_{t-1}+\left[\begin{array}{l}
v_{t} \\
u_{t} \\
0 \\
w_{t}
\end{array}\right]=\bar{\mu}_{s_{t}}+F \xi_{t-1}+V_{t} \quad \text { State equation }
\end{aligned}
$$

where

and

$$
E\left(V_{t} V_{t}^{\prime}\right)=Q_{S_{t}}
$$

$$
Q_{S_{t}}=\left[\begin{array}{cccc}
\sigma_{v, S_{t}}^{2} & 0 & 0 & 0 \\
0 & \sigma_{u, S_{t}}^{2} & 0 & 0 \\
0 & 0 & 0 & 0 \\
0 & 0 & 0 & \sigma_{w, S_{t}}^{2}
\end{array}\right]
$$

Estimation can be carried out by approximate maximum likelihood (Kim, 1994) using the GAUSS routines supplied by Kim (see Kim and Nelson, 1999a, 1999b, chapter 5). 


\section{Data and Results}

We analyse the logarithms of quarterly real GDP (output) for the G-7 countries. All of the data come from Datastream, which in turn takes the data from different sources. The sample periods are as follows: Canada, 1957:1 - 1999:4; France, 1965:1 - 1999:4; Germany, 1960:1 - 1999:4; Italy, 1970:1 - 1999:4; Japan, 1955:2 - 1999:4; U.K., 1955:1 - 1999:4; U.S., 1950:1 - 2000:1.

Table 1 summarises the results for the U.S. and the U.K., where model 1 is the unrestricted version described above and models 2 and 3 are restricted versions that impose $\sigma_{w}=0$ and $\sigma_{u, 1}^{2}=\sigma_{u, 0}^{2}=0$, respectively.

Looking first at the results for the U.S., we find that, not surprisingly, they are very similar to those reported by Kim and Nelson (1999a), although they use a somewhat different sample period to that employed here (they use 1951:1 - 1995:3). The sum of the autoregressive cycle coefficients, $\phi_{1}+\phi_{2}$, for the transitory component is 0.7147, a little smaller than that reported by Kim and Nelson, (0.7969), suggesting that once output is plucked down by negative transitory shocks, their effects decay relatively faster after incorporating recent data. The estimated coefficients yield a pair of complex autoregressive roots implying a period of 11 quarters. Comparing the likelihood values for the two models, the LR test statistics for the hypothesis $\sigma_{w}=0$ is 3.77 , rejecting the null at a $p$-value of 0.052 , a slightly stronger rejection than Kim and Nelson, for whom the test statistic was 3.44. We thus conclude that U.S. trend growth has not been constant. Like Kim and Nelson, the LR statistic for the joint hypothesis that $\sigma_{u, 1}^{2}=\sigma_{u, 0}^{2}=0$ allows us to accept the null at a very high $p$-value $(0.30)$, thus implying that the discrete shock explains most of the dynamics in the transitory component. During normal times, the economy is thus subject to mostly permanent shocks and is operating near its trend ceiling. During recessions and the recovery periods that follow, however, the transitory component plays a major role in producing output fluctuations. Note that $\hat{\pi}=-0.01$ and is clearly significantly negative.

The estimated model is thus consistent with Kim and Nelson (1999a) and their interpretation bears repeating. The estimate $\hat{q}=0.9554$ implies that the expected duration of a 'normal' regime is 22 quarters, while $\hat{p}=0.9214$ implies an expected duration of recession of 13 quarters. The steady state probabilities of being in a normal or recessionary regime are 0.64 and 0.36 , respectively. (The expected duration of a normal regime, for example, is given by $1 /(1-q)$, while the steady state probability is $(1-p) /(2-p-q))$. The onset of a recession thus produces a sequence of negative transitory shocks which 'pluck' output down, although with $\phi_{1}+\phi_{2}=0.71$, their effects decay reasonably quickly. Near the end of the recession, and in the absence of further negative shocks, the fast-decaying negative shocks give rise to a 
third, high-recovery phase, moving the economy back near the trend ceiling again. There is thus, à la Sichel (1994), three distinctive phases of business cycle dynamics: a normal, a recessionary, and a high growth, recovery phase.

Figure 1(a), which shows $y_{t}$ and filtered estimates of the trend ceiling component, $\tau_{t}$, reveals that most of the time the U.S. economy is operating at or near to the trend ceiling. Kim and Nelson, 1999b, provide details of the construction of filtered estimates: the first five years of each sample are omitted from these plots so that we can focus on filtered estimates that have 'settled down'. Figures 1(b) and 1(c) show filtered estimates of the transitory component, $c_{t}$, and the probability of a negative shock to the transitory component, i.e., the probability that $S_{t}=1$ conditional on information up to $t-1$.

Table 1 Estimated models for U.S. and U.K.

\begin{tabular}{|c|c|c|c|c|c|c|}
\hline & \multicolumn{3}{|c|}{ U.S. } & \multicolumn{3}{c|}{ U.K. } \\
\hline Parameter & Model 1 & Model 2 & Model 3 & Model 1 & Model 2 & Model 3 \\
\hline$p$ & 0.9330 & 0.9271 & 0.9214 & 0.9706 & 0.9708 & 0.9708 \\
& $(0.0452)$ & $(0.0428)$ & $(0.0442)$ & $(0.0194)$ & $(0.0192)$ & $((0.0190)$ \\
\hline$q$ & 0.9649 & 0.9393 & 0.9554 & 0.9531 & 0.9535 & 0.9535 \\
& $(0.0254)$ & $(0.0367)$ & $(0.0252)$ & $(0.0368)$ & $(0.0354)$ & $(0.0352)$ \\
\hline$\phi_{1}$ & 1.3285 & 1.5643 & 1.3189 & 1.4723 & 1.4770 & 1.4770 \\
& $(0.1266)$ & $(0.1084)$ & $(0.1095)$ & $(0.2314)$ & $(0.2074)$ & $(0.2021)$ \\
\hline$\phi_{2}$ & -0.6138 & -0.7125 & -0.6350 & -0.6860 & -0.6916 & -0.6916 \\
& $(0.1181)$ & $((0.0861)$ & $(0.1298)$ & $(0.2246)$ & $(0.1991)$ & $(0.1942)$ \\
\hline$\sigma_{u, 0}$ & 0.0014 & 0.0001 & - & 0.0003 & 0.0000 & - \\
& $(0.0013)$ & $(0.0034)$ & & $(0.0021)$ & $(0.0000)$ & \\
\hline$\sigma_{u, 1}$ & 0.00005 & 0.00004 & - & 0.0000 & 0.0000 & - \\
& $(0.0013)$ & $(0.0012)$ & & $(0.0003)$ & $(0.0001)$ & \\
\hline$\sigma_{v, 0}$ & 0.0050 & 0.0051 & 0.0051 & 0.0031 & 0.0032 & 0.0032 \\
& $(0.0009)$ & $(0.0005)$ & $(0.0007)$ & $(0.0004)$ & $(0.0003)$ & $(0.0003)$ \\
\hline$\sigma_{v, 1}$ & 0.0115 & 0.0113 & 0.0115 & 0.0120 & 0.0120 & 0.0120 \\
& $(0.0013)$ & $(0.0010)$ & $(0.0013)$ & $(0.0008)$ & $(0.0008)$ & $(0.0008)$ \\
\hline$\sigma_{w}$ & 0.0008 & - & 0.0008 & 0.0000 & - & 0.0000 \\
& $(0.0004)$ & & $(0.0004)$ & $(0.0000)$ & & $(0.0000)$ \\
\hline$\pi$ & -0.0099 & -0.0062 & -0.0098 & -0.0039 & -0.0039 & -0.0039 \\
& $(0.0027)$ & $(0.0015)$ & $(0.0027)$ & $(0.0022)$ & $(0.0021)$ & $(0.0020)$ \\
\hline Log L'lihood & 607.359 & 605.473 & 607.211 & 528.842 & 528.840 & 528.840 \\
\hline
\end{tabular}


The transitory component and the probability of negative shocks correlate highly with NBER recessionary periods, as discussed in Kim and Nelson (1999a). The figures also show that, apart from a brief period in the early 1990s (no doubt a consequence of the Gulf war and the accompanying oil price shocks), the economy has been running at ceiling output since 1985. This is consistent with the view that this is the longest period of sustained expansion in U.S. economic history, typically attributed to the fact that macroeconomic policy has kept inflation firmly under control (Romer, 1999).

For the U.K. the sum of the AR coefficients is $\phi_{1}+\phi_{2}=0.7863$, a little higher than for the U.S. The estimated coefficients again imply complex roots with a period of 13 quarters. Testing $\sigma_{w}=0$ by comparing models 1 and 2 produces an LR statistic of 0.004 , which therefore strongly supports the hypothesis that the variance of trend growth rate is zero. This suggests that the trend component is only subject to level shocks and that over this period trend growth has been constant, unlike the U.S. Comparing models 1 and 3 provides a test of the joint hypothesis that $\sigma_{u, 1}^{2}=\sigma_{u, 0}^{2}=0$. The LR statistic of 0.004 obviously accepts the hypothesis, implying that, as in the U.S., discrete shocks explain most of the dynamics in the transitory component. The estimate of the impact of such shocks is $\hat{\pi}=-0.004$, which is again negative but rather smaller than for the U.S., while the estimates of $\hat{p}$ and $\hat{q}$ imply expected durations of 34 and 22 quarters for recession and normal phases respectively, with steady state probabilities of 0.61 and 0.39 . The implications of these estimates are seen in Figure 2. Figures 2(a) and 2(b) show that, unlike the U.S., output has consistently been below its ceiling level for the great majority of the sample period. Only since the mid-1990s has a lengthy period of 'normal' growth been achieved, which corresponds well with contemporary views of the behaviour of the U.K. economy (Bean and Crafts, 1996). The last five years of the sample are clearly unusual, for Figure 2(c) shows that only the mid-1960s approximate in terms of the prolonged absence of negative shocks.

Table 2 reports unrestricted estimates of the model for the other G-7 countries, while Table 3 reports estimates of restricted models, where insignificant parameters have been set to zero. All restrictions are accepted at very high $p$-values, as can be seen by comparing the respective log-likelihoods in the two tables. Figures 3 to 7 present similar sets of plots to those presented for the U.S. and the U.K.

Compared with the U.S. and the U.K., these models provide a variety of interpretations. Like the U.S., but unlike the U.K., estimates of $q$ are always greater than $p$, implying that recessions have shorter expected durations and lower steady state probabilities than normal phases. These probabilities vary from 0.37 for Japan to 0.83 for Germany, and all are much lower than for the U.S. and the U.K. Estimates 
of shock persistence, $\phi_{1}+\phi_{2}$, range from 0.5886 for Germany to 0.9458 for Canada, and for Japan and France the transitory components exhibit exponential rather than pseudo-cyclical behaviour. Only for France and Italy can the 'trend ceiling' hypothesis $\sigma_{u, 1}^{2}=\sigma_{u, 0}^{2}=0$ be accepted. For Japan and Canada only $\sigma_{u, 1}^{2}=0$, so that just 'normal' symmetric shocks effect the transitory component, whereas the situation is reversed for Germany, which is affected only by symmetric recessionary shocks. On the other hand, regime dependent level shocks are observed for all countries, and only for Germany is $\sigma_{w}=0$, so that, like the U.K., trend growth has remained constant. The evidence in favour of 'plucking' is somewhat mixed - although $\pi$ is always negative, it is not significantly so for Japan or Germany.

Table 2 Estimated unrestricted models for the other G-7 countries

\begin{tabular}{|c|c|c|c|c|c|}
\hline Parameters & Canada & France & Italy & Germany & Japan \\
\hline$p$ & 0.6144 & 0.7312 & 0.5539 & 0.8257 & 0.2945 \\
& $(0.3359)$ & $(0.1970)$ & $(0.1604)$ & $(0.1186)$ & $(0.2447)$ \\
\hline$q$ & 0.9866 & 0.9439 & 0.9786 & 0.9716 & 0.8974 \\
& $(0.0138)$ & $(0.0758)$ & $(0.0242)$ & $(0.0249)$ & $(0.1194)$ \\
\hline$\phi_{1}$ & 1.5411 & 0.4964 & 1.4931 & -0.0234 & 1.0827 \\
& $(0.2520)$ & $(0.4467)$ & $(0.1404)$ & $(0.1062)$ & $(0.1842)$ \\
\hline$\phi_{2}$ & -0.5852 & 0.3363 & -0.6116 & 0.5223 & -0.2196 \\
& $(0.2253)$ & $(0.3776)$ & $(0.1675)$ & $(0.1748)$ & $(0.1870)$ \\
\hline$\sigma_{u, 0}$ & 0.0043 & 0.0015 & 0.0013 & 0.00001 & 0.0069 \\
& $(0.0021)$ & $(0.0034)$ & $(0.0023)$ & $(0.0002)$ & $(0.0012)$ \\
\hline$\sigma_{u, 1}$ & 0.00001 & 0.0057 & 0.00001 & 0.0083 & 0.00002 \\
& $(0.0003)$ & $(0.0049)$ & $(0.0004)$ & $(0.0041)$ & $(0.0002)$ \\
\hline$\sigma_{v, 0}$ & 0.0073 & 0.0056 & 0.0051 & 0.0093 & 0.0001 \\
& $(0.0013)$ & $(0.0016)$ & $(0.0009)$ & $(0.0008)$ & $(0.0018)$ \\
\hline$\sigma_{v, 1}$ & 0.0047 & 0.0054 & 0.0034 & 0.0161 & 0.0180 \\
& $(0.0024)$ & $(0.0066)$ & $(0.0008)$ & $(0.0049)$ & $(0.0059)$ \\
\hline$\sigma_{w}$ & 0.0006 & 0.0012 & 0.0008 & 0.0003 & 0.0015 \\
& $(0.0004)$ & $(0.0005)$ & $(0.0003)$ & $(0.0004)$ & $(0.0005)$ \\
\hline$\pi$ & -0.0145 & -0.0081 & -0.0103 & -0.0128 & -0.0030 \\
& $(0.0044)$ & $(0.0036)$ & $(0.0029)$ & $(0.0087)$ & $(0.0051)$ \\
\hline Log L'lihood & 490.94 & 418.23 & 365.59 & 427.32 & 511.20 \\
\hline
\end{tabular}


Table 3 Estimated restricted models for the other G-7 countries

\begin{tabular}{|c|c|c|c|c|c|}
\hline Parameters & Canada & France & Italy & Germany & Japan \\
\hline$p$ & 0.6143 & 0.6871 & 0.5582 & 0.8339 & 0.3728 \\
& $(0.2229)$ & $(0.2781)$ & $(0.1509)$ & $(0.1186)$ & $(0.2870)$ \\
\hline$q$ & 0.9866 & 0.9305 & 0.9824 & 0.9774 & 0.9275 \\
& $(0.0138)$ & $(0.1195)$ & $(0.0201)$ & $(0.0232)$ & $(0.0870)$ \\
\hline$\phi_{1}$ & 1.5411 & 0.8557 & 1.5458 & - & 0.9004 \\
& $(0.2399)$ & $(0.1035)$ & $(0.1271)$ & & $(0.0654)$ \\
\hline$\phi_{2}$ & -0.5953 & - & -0.6705 & 0.5886 & - \\
& $(0.2149)$ & & $(0.1404)$ & $(0.1677)$ & \\
\hline$\sigma_{u, 0}$ & 0.0043 & - & - & - & 0.0072 \\
& $(0.0020)$ & & & & $(0.0012)$ \\
\hline$\sigma_{u, 1}$ & - & - & - & 0.0095 & - \\
& & & & $(0.0050)$ & \\
\hline$\sigma_{v, 0}$ & 0.0073 & 0.0059 & 0.0054 & 0.0097 & - \\
& $(0.0013)$ & $(0.0010)$ & $(0.0005)$ & $(0.0008)$ & \\
\hline$\sigma_{v, 1}$ & 0.0047 & 0.0091 & 0.0035 & 0.0170 & 0.0184 \\
& $(0.0023)$ & $(0.0033)$ & $(0.0007)$ & $(0.0046)$ & $(0.0067)$ \\
\hline$\sigma_{w}$ & 0.0006 & 0.0010 & 0.0008 & - & 0.0017 \\
& $(0.0003)$ & $(0.0005)$ & $(0.0003)$ & & $(0.0006)$ \\
\hline$\pi$ & -0.0145 & -0.0068 & -0.0094 & - & - \\
& $(0.0042)$ & $(0.0038)$ & $(0.0021)$ & & \\
\hline Log L'lihood & 490.94 & 417.96 & 365.58 & 426.11 & 509.84 \\
\hline
\end{tabular}

Figure 3 shows that Canadian output has been close to its ceiling value except for two major episodes - throughout most of the 1980s and, like the U.S. and the U.K., during the early 1990s. The recesssions are seen to be a consequence of two major negative shocks to the transitory component of output. Canada was particularly affected in the early 1980s by shifts in international trade patterns and also by labour market rigidities caused by provincial disparities and structural differences. As noted above, Canada has the greatest shock persistence of all the G-7 countries, and this is seen in the length of the two recessions.

From Figure 4, we see that France has been consistently below its output ceiling, with the large deviations in the 1970s being a consequence of it adapting only with difficulty to wage and oil shocks. The 1981-83 decline was related to the 
succession of exchange rate crises that eventually led to a major shift in macroeconomic policy by the Mitterand administration, who then followed more market-oriented policies which produced a more stable growth path (Sicsic and Wyplosz, 1996).

By comparison, Germany has tended to be rather closer to trend, although with some rather volatile fluctuations during the late 1960s and early 1970s (see Figure 5). These were probably a consequence of the recession of 1966-67, which produced a fall in employment as well as in output. This, in turn, led to significant changes in work practices and a subsequent loss of discipline by both unions and employers associations, manifesting itself in wild-cat strikes, which were exacerbated by an appreciation of the exchange rate. Such instability ended after the floating of the Deutschmark in 1973 and the adoption by the Bundesbank of a tight nonaccommodating monetary policy (see Carlin, 1996).

Italy, whose sample period only begins in 1970, was well below its ceiling until the mid-1980s, but since then has been very close to trend except for 1992 to 1995 (see Figure 6). The poor performance during late 1970s and early 1980s undoubtedly had its origins earlier, for the social and institutional developments of the previous decade, which led to a succession of weak government coalitions, made the Italian economy more vulnerable to exogenous shocks, particularly as the country was also hit by waves of terrorism. The stable performance throughout the 1980s was a reflection of a new commitment to exchange rate stability, industrial restructuring and improved labour relations. Nevertheless, government borrowing remained out of control and this precipitated the poor performance of the early 1990s (Rossi and Toniolo, 1996).

Finally, from Figure 7, Japan has always been close to trend, but this masks the fact that throughout the first half of the 1990s the transitory component has been negative, reflecting the long recession after the stock market crash at the start of the decade. As output moved back to its ceiling level in 1997, a large negative shock (associated with the major tax increase in that year) tipped the economy back into recession again, in which it has remained.

\section{Conclusions}

Friedman's plucking model, as rigorously formulated by Kim and Nelson (1999a,b), offers an interesting approach to investigating asymmetries in business cycles. On fitting this model to output data from the G-7 countries, we have found a fair degree of support for it. Negative asymmetric discrete shocks are found to influence the transitory component of output of each country, so that there does seem to be evidence for the downward recessionary 'plucks' envisaged by Friedman (1964, 
1993). The evidence of a ceiling level for output is less widespread, being accepted for the U.S., the U.K., France and Italy, but not for Canada, Japan and Germany. The hypothesis of constant trend growth can only be accepted for the U.K. and Germany and typically both normal and recessionary symmetric shocks influence trend output.

The deviations of actual from estimated trend output for each country accords well with macroeconomic history, although the length and depth of recessions vary widely and only for the U.K. is the expected duration of a recession longer than that of a 'normal' period. Nevertheless, our results for the wider set of G-7 economies are consistent with those found by Kim and Nelson (1999a) for the U.S. Output during normal times seems to be driven mostly by permanent shocks, but during recessions and high-growth recoveries, transitory shocks dominate, so that during these periods macroeconomic models that emphasise demand-oriented shocks, rather than real business cycle type models, may be more appropriate.

\section{References}

Artis, M.J. and Zhang, W.D. (1999). "Further Evidence on International Business Cycle and the ERM: is there a European Business Cycle?", Oxford Economic Papers, 51, 120-132.

Artis, M.J., Kontolemis, Z.G. and Osborn, D.R. (1997), "Business cycles for G7 and European countries", Journal of Business, 70, 249-279.

Bean, C. and Crafts, N. (1996), "British economic growth since 1945: relative economic decline ... and renaissance?", in N. Crafts and G. Toniolo (editors), Economic growth in Europe since 1945, 131-172, Cambridge, Cambridge University Press.

Birchenhall, C.R., Jessen, H., Osborn, D.R. and Simpson, P.W. (1999), "Predicting US business cycle regimes", Journal of Business and Economic Statistics, 17, 313-323.

Carlin, W. (1996), “West German growth and institutions, 1945-90”, in N. Crafts and G. Toniolo (editors), Economic growth in Europe since 1945, 455-497, Cambridge, Cambridge University Press.

Clark, P.K. (1987), "The cyclical component of the U.S. economic activity", Quarterly Journal of Economics, 102, 797-814. 
Friedman, M. (1964), "Monetary studies of the National Bureau", The National Bureau Enters its $45^{\text {th }}$ Year, $44^{\text {th }}$ Annual Report, pp. 7-25.

Friedman, M. (1993), “The 'plucking model' of business fluctuations revisited", Economic Inquiry, 31, 171-177.

Goodwin, T.H. and Sweeney, R.J. (1993), “International evidence on Friedman's theory of the business cycle", Economic Inquiry, 31, 178-193.

Hamilton, J.D. (1989), “A new approach to the economic analysis of nonstationary time series and the business cycle", Econometrica, 57, 357-384.

Kim, C.J. (1994), "Dynamic linear models with Markov-switching”, Journal of Econometrics, 60, 1-22.

Kim, C.J and Nelson, C.R. (1999a), "Friedman's plucking model of business fluctuations: tests and estimations of permanent and transitory components", Journal of Money, Credit and Banking, 31, 317-334.

Kim, C.J. and Nelson, C.R. (1999b), State-space models with regime switching: Classical and Gibbs-sampling approaches with applications, Cambridge, Mass., MIT Press.

Nadir Ö. and Osborn, D.R. (2000), "Business cycle non-linearities in UK consumption and production", Journal of Applied Econometrics, 15, 27-43.

Romer, C.D. (1999), "Changes in business cycles: Evidence and explanations", Journal of Economic Perspectives, 13(2), 23-44.

Rossi, N. and Toniolo, G. (1996), "Italy", in N. Crafts and G. Toniolo (editors), Economic growth in Europe since 1945, 427-454, Cambridge, Cambridge University Press.

Sichel, D. E. (1994), "Inventories and the three phases of the business cycle", Journal of Business and Economic Statistics, 12, 269-277. 
Sicsic, P. and Wyplosz, C. (1996), "France, 1945-92", in N. Crafts and G. Toniolo (editors), Economic growth in Europe since 1945, 210-239, Cambridge, Cambridge University Press.

Simpson, P.W., Osborn, D.R. and Sensier, M. (2000), "Modelling Business Cycle Movements in the UK Economy", Economica. 
Figure 1: Plucking model decompositions for the U.S.

(a) Output, $y_{t}$, and trend component, $\tau_{t}$

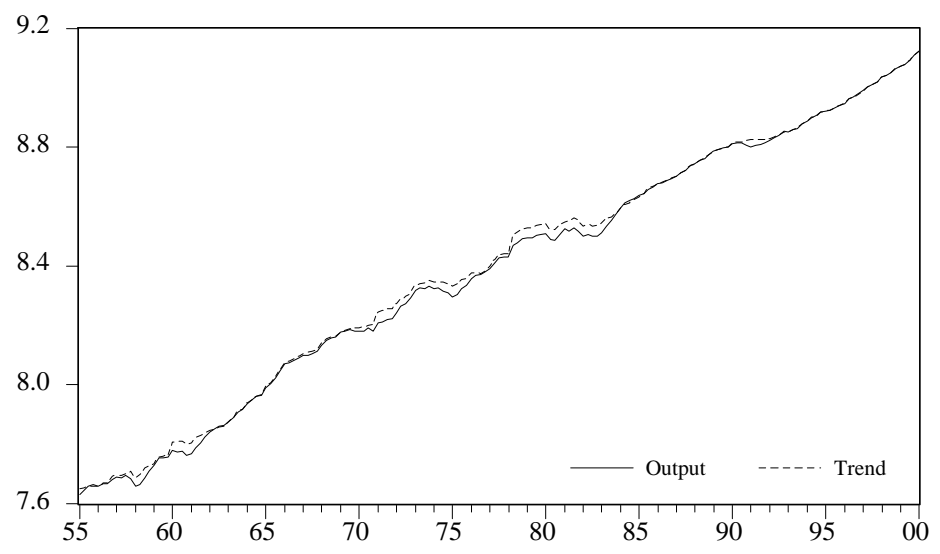

(b) Transitory component, $c_{t}$

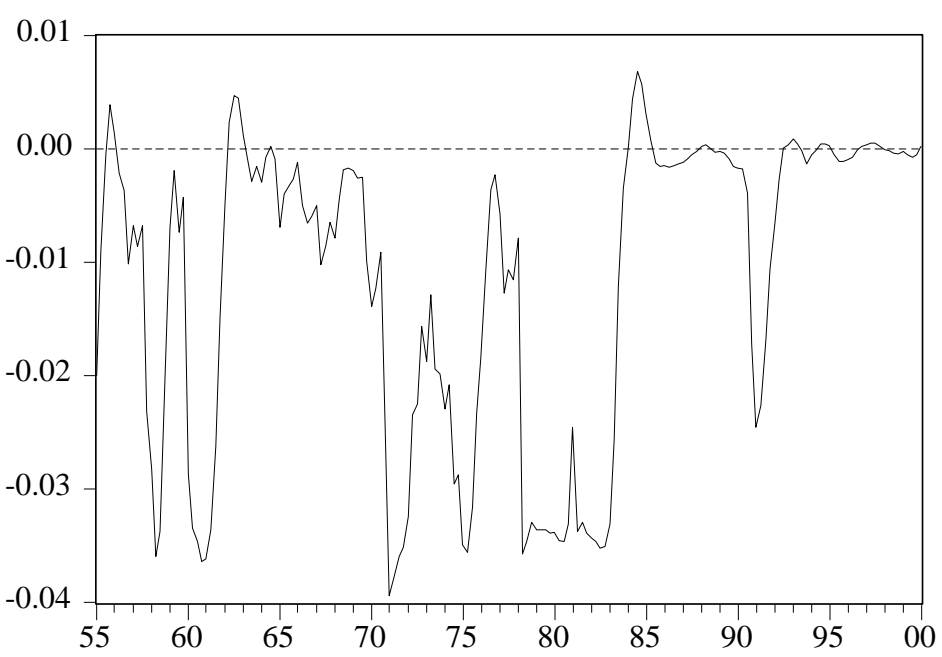

(c) Probabilities of negative shocks to $c_{t}$

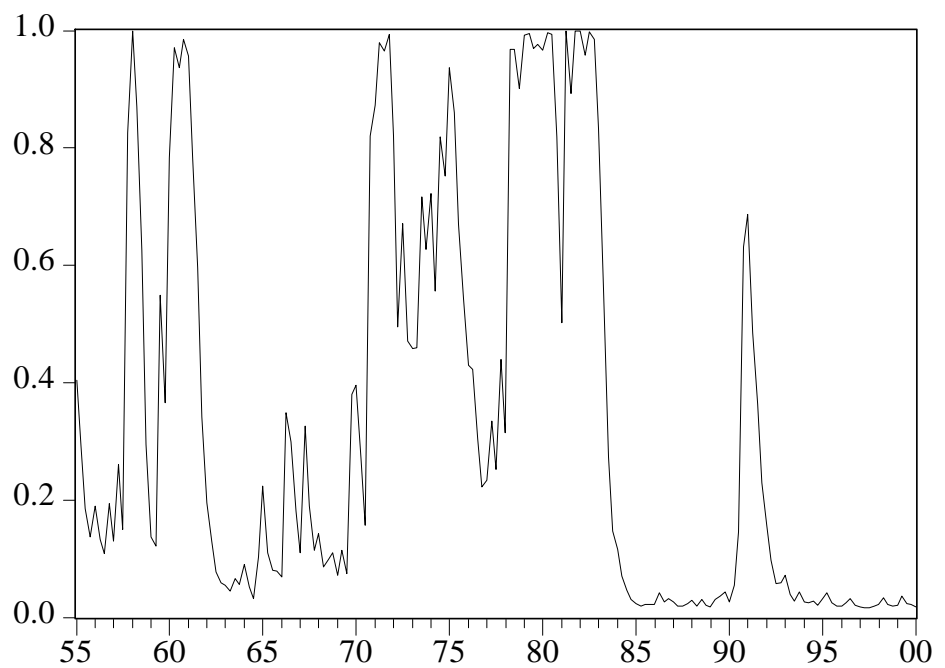


Figure 2: Plucking model decompositions for the U.K.

(a) Output, $y_{t}$, and trend component, $\tau_{t}$

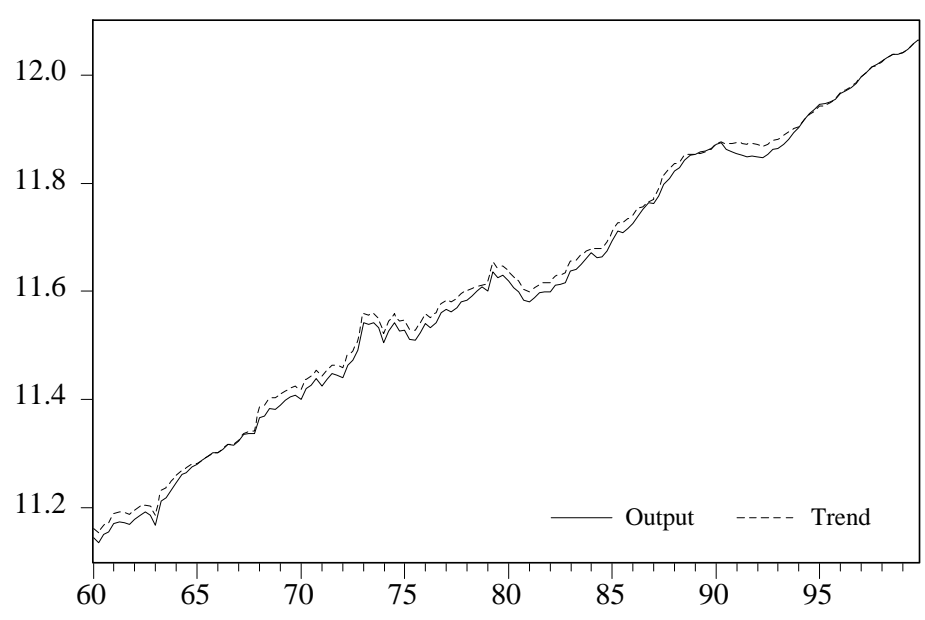

(b) Transitory component, $c_{t}$

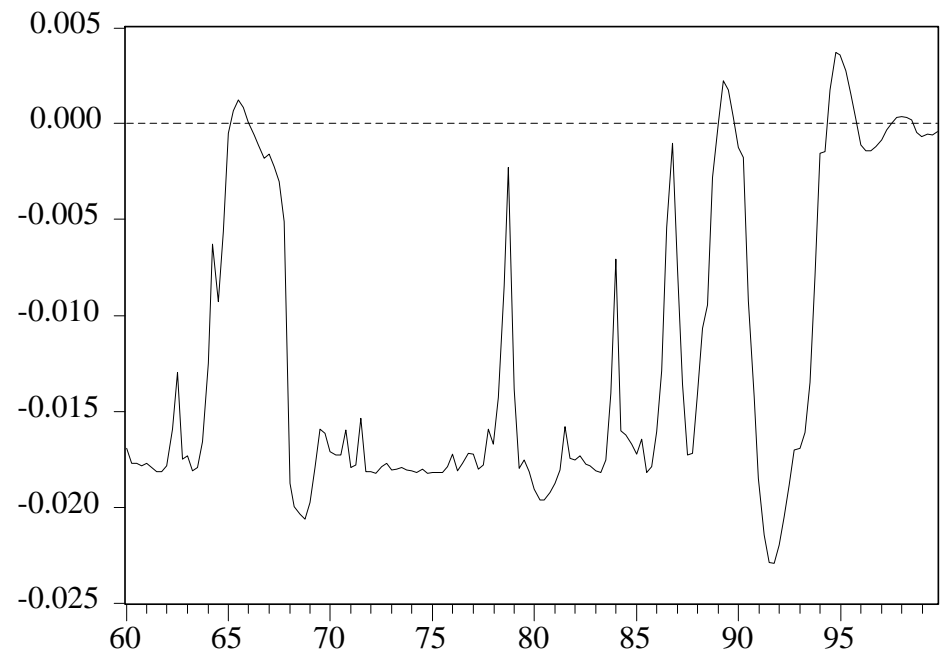

(c) Probabilities of negative shocks to $c_{t}$

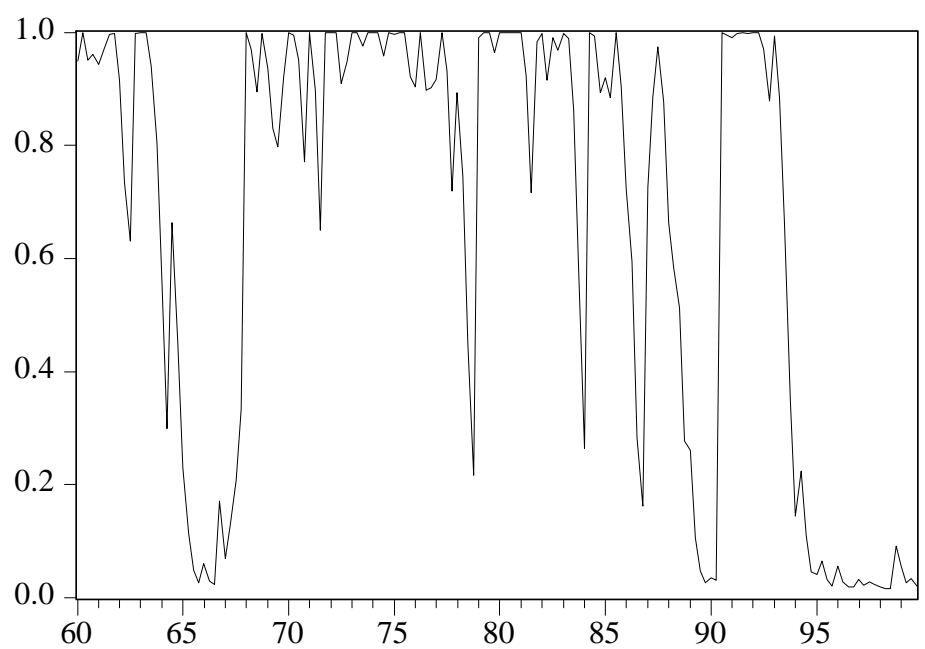


Figure 3: Plucking model decompositions for Canada

(a) Output, $y_{t}$, and trend component, $\tau_{t}$

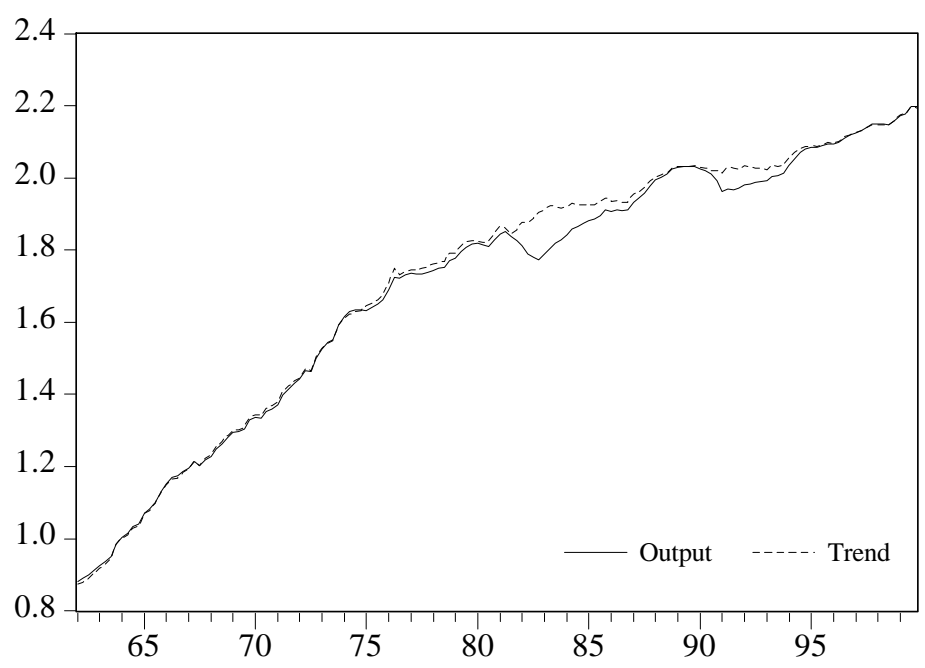

(b) Transitory component, $c_{t}$

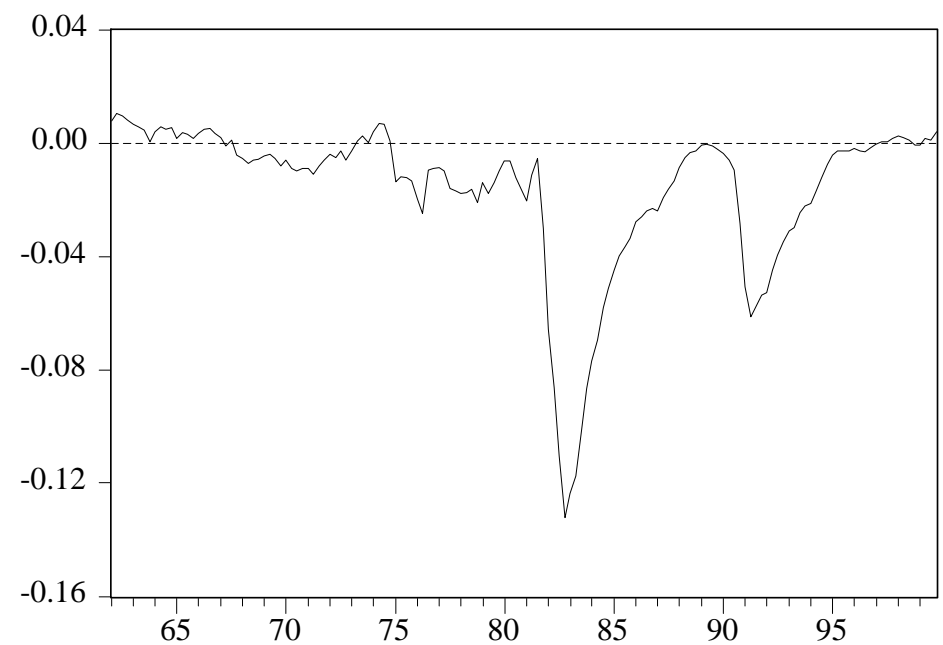

(c) Probabilities of negative shocks to $c_{t}$

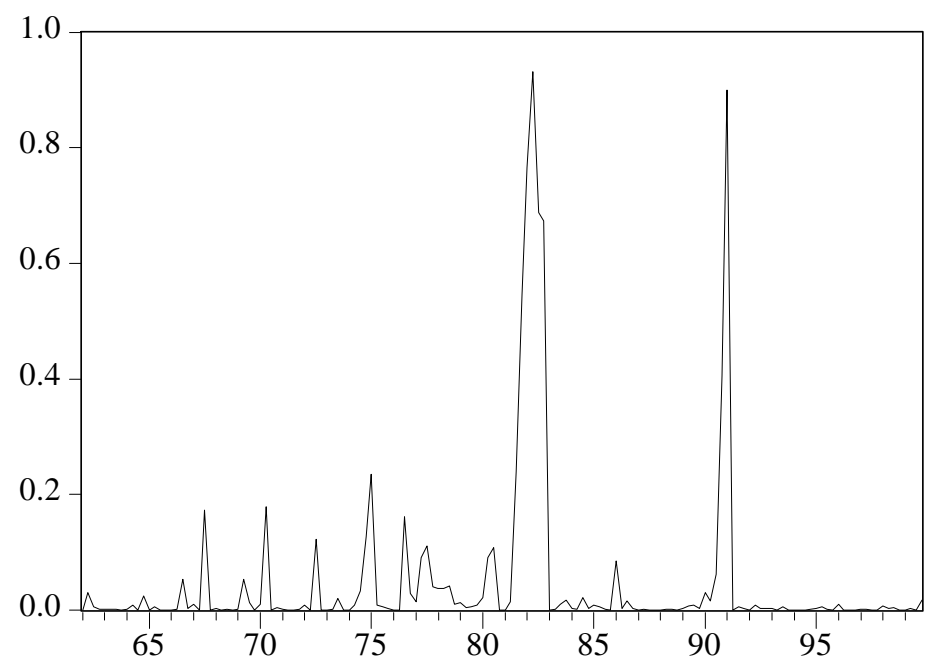


Figure 4: Plucking model decompositions for France

(a) Output, $y_{t}$, and trend component, $\tau_{t}$

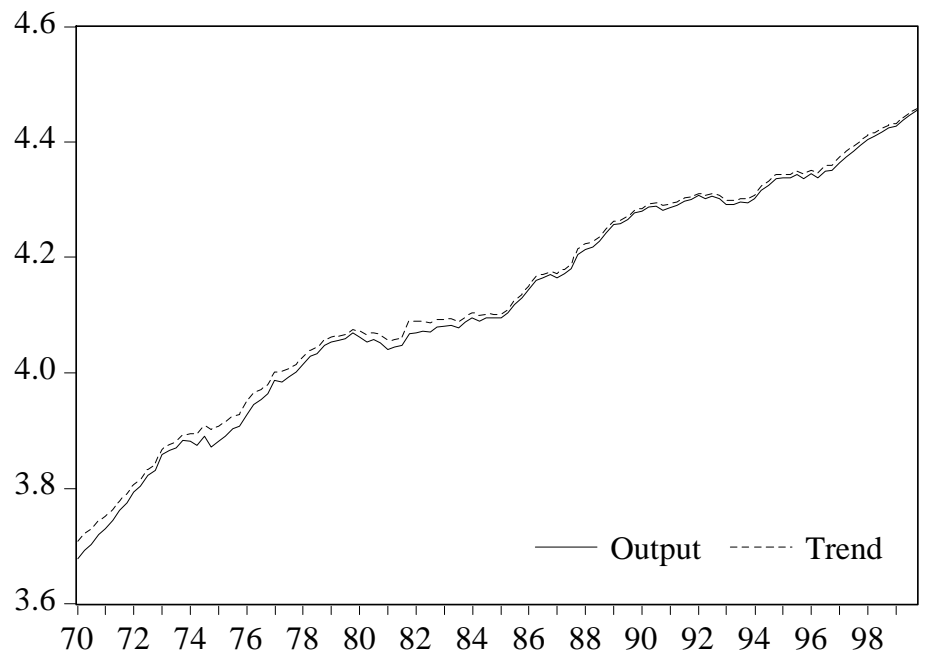

(b) Transitory component, $c_{t}$

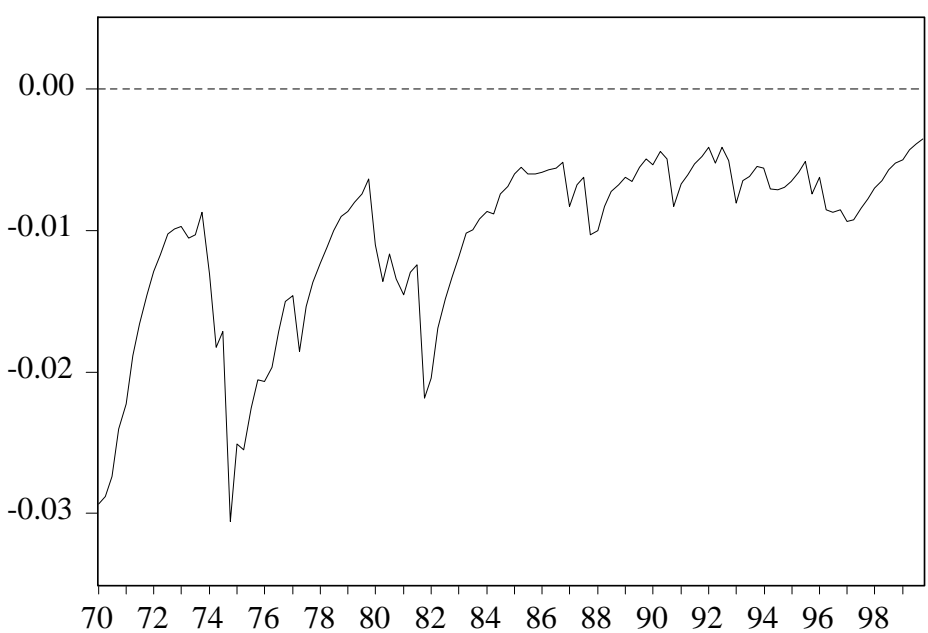

(c) Probabilities of negative shocks to $c_{t}$

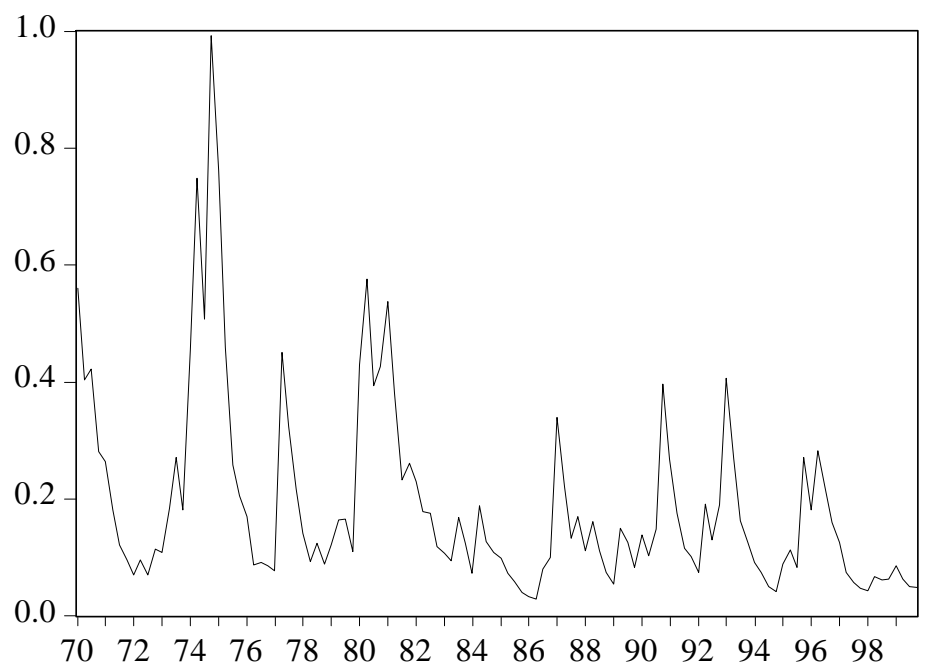


Figure 5: Plucking model decompositions for Germany

(a) Output, $y_{t}$, and trend component, $\tau_{t}$

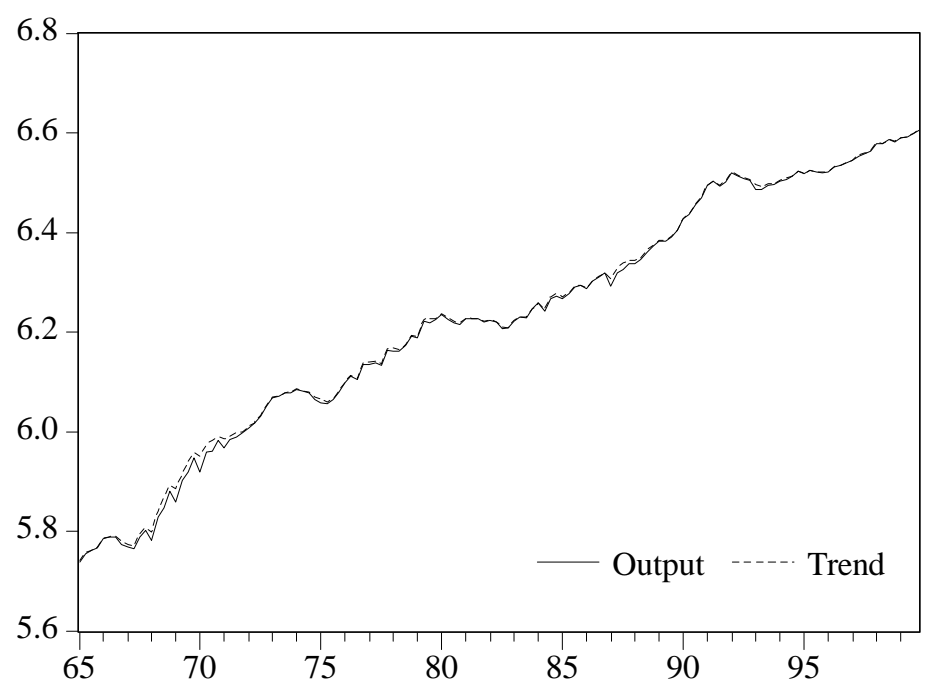

(b) Transitory component, $c_{t}$

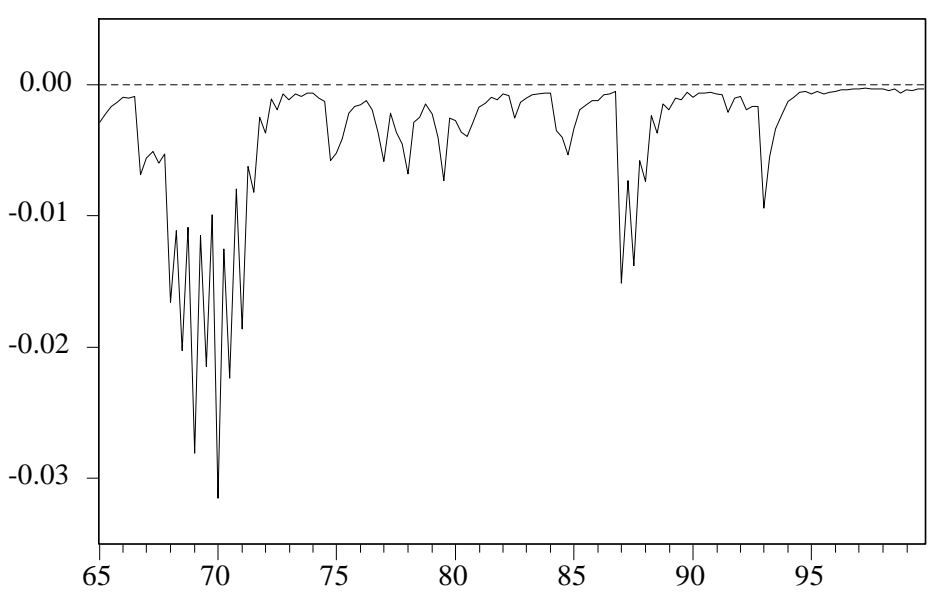

(c) Probabilities of negative shocks to $c_{t}$

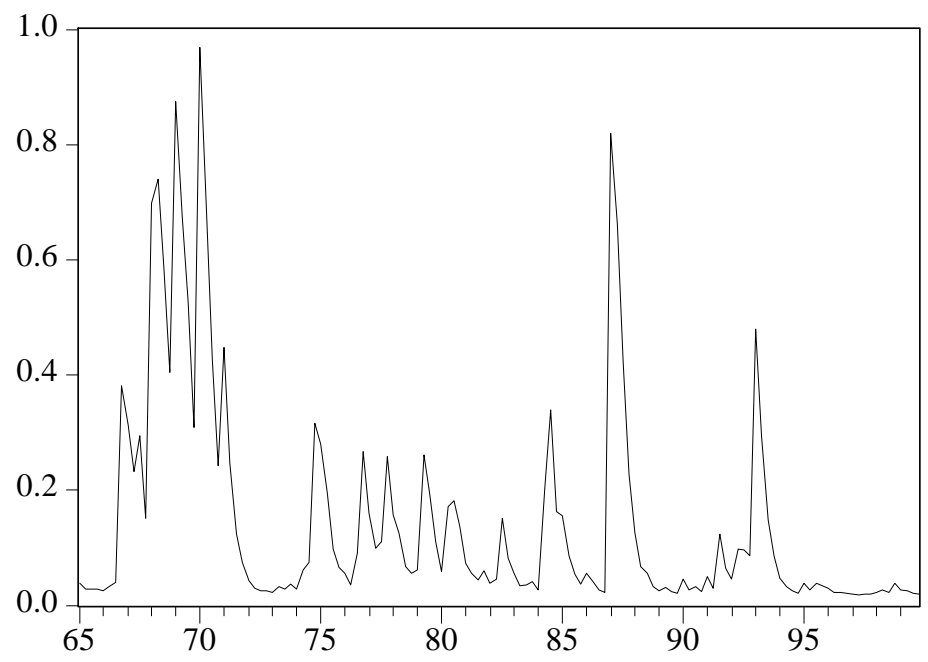


Figure 6: Plucking model decompositions for Italy

(a) Output, $y_{t}$, and trend component, $\tau_{t}$

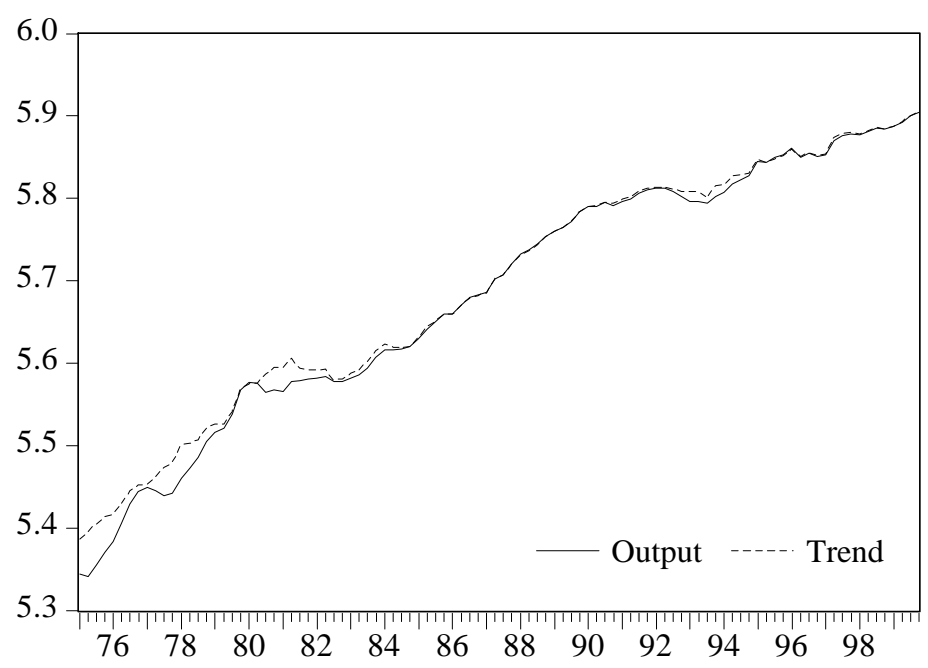

(b) Transitory component, $c_{t}$

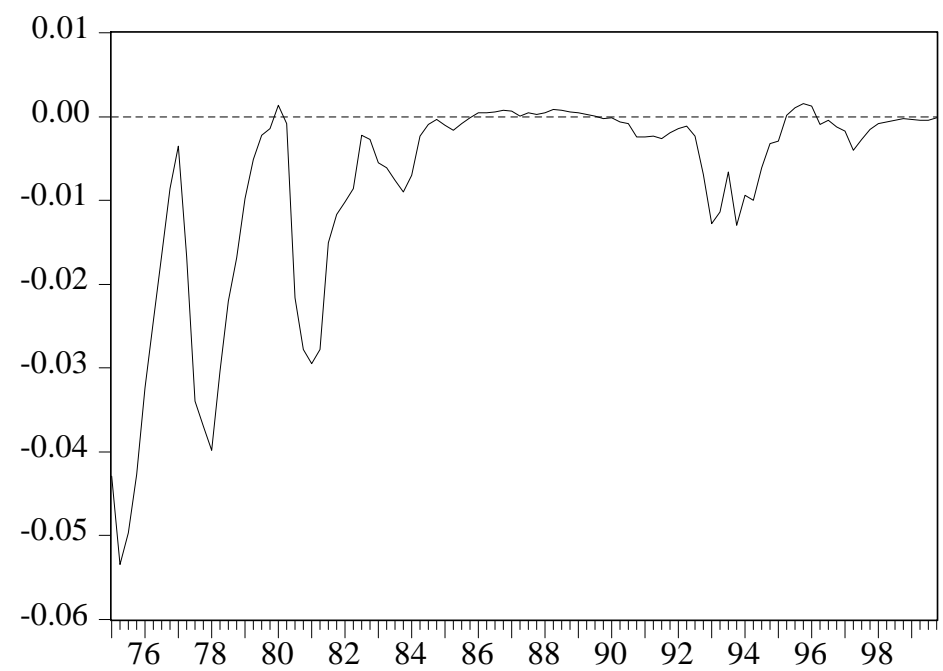

(c) Probabilities of negative shocks to $c_{t}$

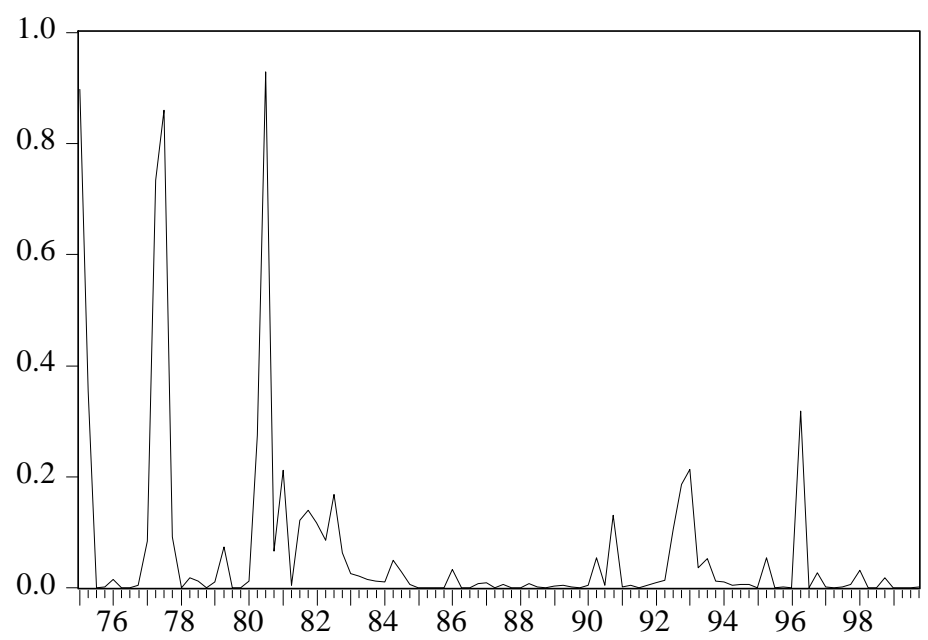


Figure 7: Plucking model decompositions for Japan

(a) Output, $y_{t}$, and trend component, $\tau_{t}$

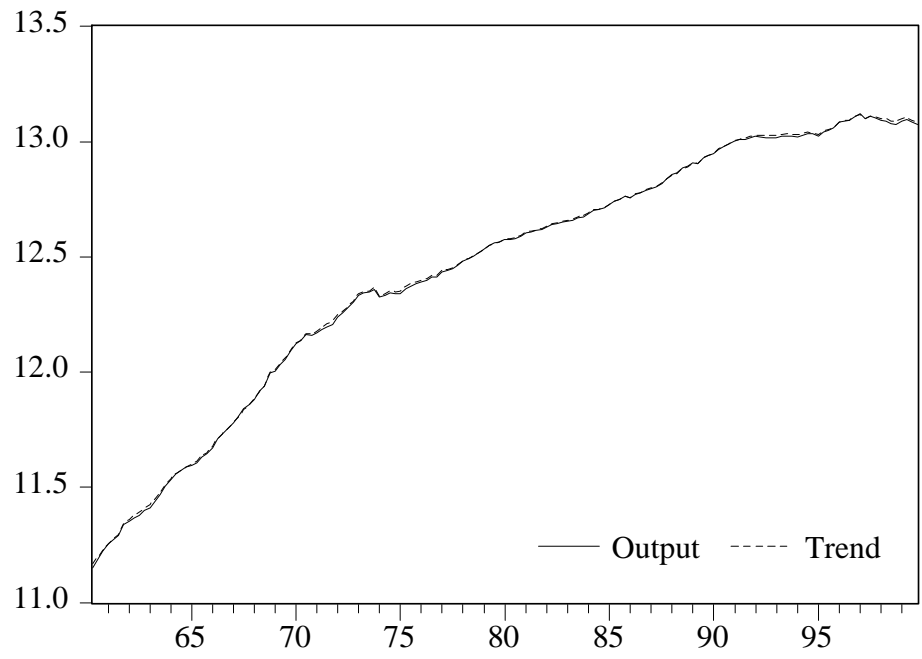

(b) Transitory component, $c_{t}$

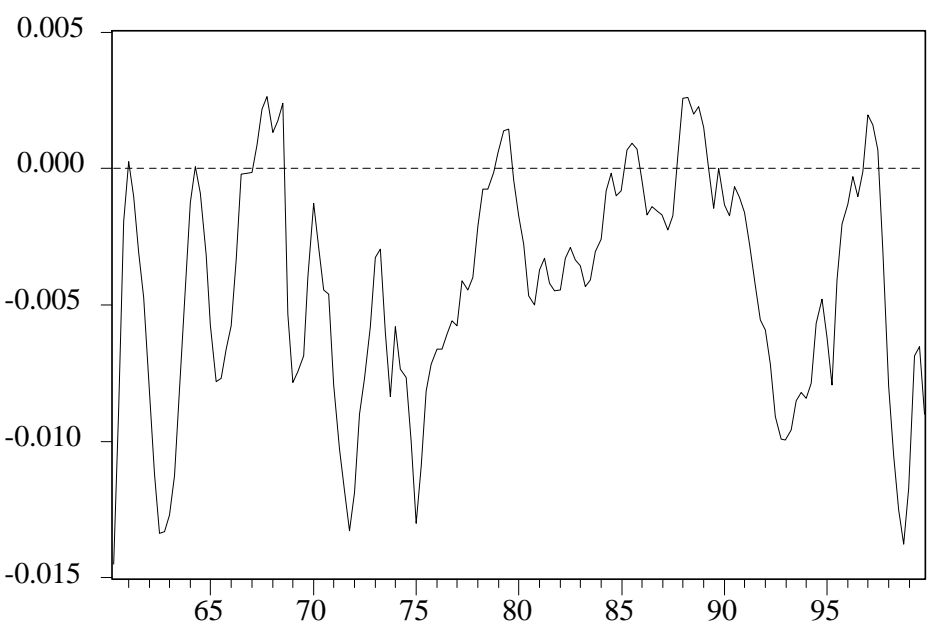

(c) Probabilities of negative shocks to $c_{t}$

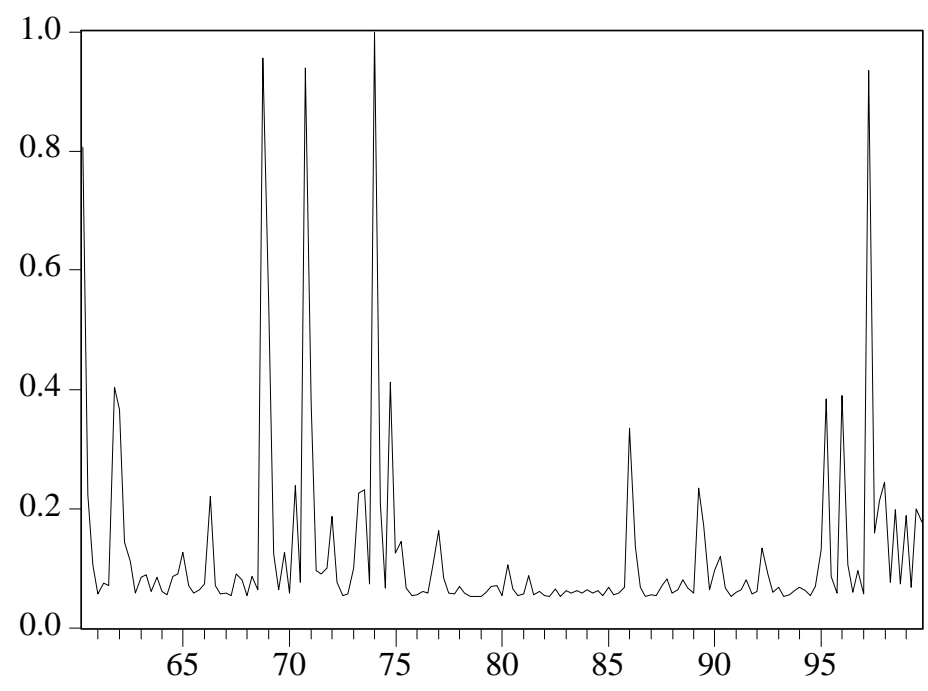


